some time with day and night training of semiskilled mechanics for armament factories, thus anticipating the Ministry of Labour scheme, and has since turned to the production of munition components. Many members of the staffs of the Departments of the Faculties of Pure Science, Medicine, Engineering and Metallurgy, have carried on research work in connexion with the war effort in addition to their normal duties. The Regional Committee for Education in H.M. Forces, centred in and worked from the University, arranged 702 lectures and talks.

\section{A Brilliant Atmospheric Arc}

OPtical phenomena appear to have been very prominent in the upper atmosphere over the southeast of England on November 9, 1941. An account of a brilliantly coloured arc has been received from Mr. A. F. Dufton, of the King's Lodge, Hunton Bridge, Herts. Although the colouring is described as fully as brilliant as that of a rainbow, the colours being in the usual sequence with the red outermost,

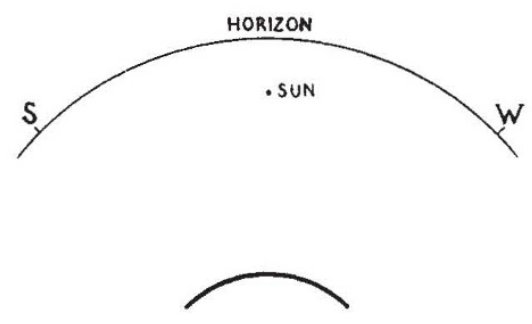

+ZENITH

the accompanying sketch, which was sent by $\mathrm{Mr}$. Dufton, shows that the are was not part of an ordinary rainbow, being parallel with the horizon. The radius of curvature was estimated to subtend about $40^{\circ}$, the sun being estimated to be about $50^{\circ}$ from the nearest point of the are (the middle of the arc). The phenomenon was seen at 4 p.m. B.s.T., and a trace of cirrus cloud was present. On the same day, Mr. L. C. H. Cave, of the Old Rectory, Blechingley, Surrey, as reported in The Times of November 24, that he saw a mock sun at Hitchin of exceptional brilliance, also at 4 p.m. B.s.T. This is described as being so bright that it was almost difficult to look directly at it.

\section{West African Forestry during 1940}

IT may be asked whether the constant reiteration of the forest policy envisaged for the several Colonies under the Colonial Office produces the results obviously aimed at by the writers of annual forestry reports. The administrative authorities pass these reports and doubtless think that these statements read well and do not commit them to anything; and results in the past have shown this to be true. A forest policy put up by the forestry adviser may be accepted in whole or in part, but ruthlessly countermanded in a few months time for reasons having no connexion with a true appreciation of the value of the forests in the interests of the community. The heads of all three forest services in West Africa, Nigeria, the Gold Coast and Sierra Leone comment in their annual reports on the absence of military duties of a high percentage of their gazetted officers. The Conservator in Sierra Leone has four assistants; yet between them they only put in 18 months work in the department during the year (1940). At the end of the same year twelve officers, about half the Gold Coast forest staff, were on military service ; while in Nigeria more than one third of the gazetted staff were on military service or other war-time duties. Yet in each Colony war-time demands are accelerating the exploitation of the forests. It is not therefore surprising that much of the work of a trained forest officer in the introduction of a proper management, such as reservation, including stock mapping preceding exploitation, in sylvicultural work with the object of the perpetuation of the forest estate, and other professional development work, was almost in abeyance during the year in all three Colonies.

It is difficult to regard this position with satisfaction in view of the recent debates in both Houses of Parliament on Colonial matters. For in each the inference was that the Colonial Office is not awaiting the end of the War, but is even now busy considering how the administrative machinery may be best speeded up and shaped so as to enable better conditions of livelihood to be enjoyed by the populations in the future. Where the improvement of agricultural practices is in question, or even education, the results -mistakes or otherwise-may become apparent within a few years. This is not the case with forestry. The postponement and procrastination displayed in the acceptance and adoption of a correct forest policy is almost a commonplace when applied to many of the Colonies ; as is a recognition that forests cannot remain in a balancing or stable condition. They are either constantly improving or degrading. The most serious result of the absence of so many officers from the forest departments is the further delay in speeding up the placing of forest areas into the category of reserves when they come under the direct management and care of the forest officer.

\section{Public Health in the United States}

ACCORDING to provisional data for 1939 compiled by the Public Health Service of the United States the general mortality in 45 States, the Districts of Columbia, Hawaii and Alaska, was $10 \cdot 7$ per 1,000 inhabitants, as compared with 10.6 in 1938 . Infantile mortality was 48 per 1,000 living births, the lowest hitherto recorded. The fall in maternal mortality continued, being 10 per cent lower than in 1938 (4. per cent live births). During the year 1939 no case of cholera or yellow fever was reported, but one case of plague was notified in the State of Utah. There were 403,037 cases of measles, or less than half the number in 1938, and 9,877 cases of smallpox as compared with 14,938 in the previous year. At the beginning of the summer of 1939 there was an outbreak of poliomyelitis in the States of the Atlantic coast with a total of 7,339 cases compared with 1,705 in 1938. The incidence of diphtheria, cerebrospinal fever, scarlet fever, typhoid and paratyphoid fevers was much less than the average for the quinquennium 1934-38. There was an outbreak of influenza in February 1939 which subsided towards the middle of July, but there was another outbreak in October which lasted until June 1940; in 1939 there were 275,503 cases notified, or more than double those in 1938 and 40 per cent above the average for the quinquennium 1934-38. 2,996 cases of typhoid fever were notified in 1939 as compared with 2,294 in 1938. The mortality from typhoid, paratyphoid, measles, scarlet fever, diphtheria, encephalitis, meningitis, tuberculosis, malaria, pellagra, affections of the 
alimentary tract, syphilis, diarrhœa and enteritis in children under two years, and accidents (including motor accidents) were the lowest reported in the last five years. The mortality from pneumonia was very low in 1939, the diminution being more than 33 per cent compared with 1938. The increases in the mortality from cancer, diabetes, cerebral hæmorrhage and heart disease must be attributed principally to the greater age of the population.

\section{Nature of the Long-period Variable Stars}

R. M. Scotr has an article on the long-pəriod variable stars in the Telescope of September-October, which provides a popular description of the type of star of which Mira is a prototype. The spectra of these stars reveal that they are cold enough to. contain molecules, and yet sufficiently hot to show the bright lines of hydrogen and ionized metals, and a brief explanation of the probable reason for this follows. Assuming that these stars are pulsating, we can picture a small core about the size of our sun surrounded by an atmosphere extending to a distance comparable with that of the earth from the sun. Viewed from a distance, one of these stars would present the appearance of a luminous fuzzy ball, deep in a hazy murk, and it is easy to imagine flames similar to solar prominences hovering deep in the smoky atmosphere near the luminous core. Then as the star approaches minimum the atmosphere would become darker and more clouded and the core a deeper red, the eruptions practically disappearing. It is possible that these red variables may be a link in the evolutionary chain, great numbers of stars starting their lives as red variables and then outgrowing their adolescent pulsations. On the other hand, redvariable pulsations may represent the palsy of stellar old age, though the former theory is the more popular of the two. At present this type of star presents a problem which can only be solved by much more investigation.

\section{William James (1842-1910)}

WrLliam James, the well-known psychologist and philosopher, was born in New York on January 11, 1842 , the son of the Swedenborgian theologian Henry James and brother of the novelist Henry James. He studied medicine at Harvard, where he qualified in 1869. He never engaged in practice, but after occupying the chairs of anatomy and physiology at Harvard, he devoted, himself entirely to psychology and philosophy. From 1889 until 1897 he was professor of psychology and from 1897 until 1907 professor of philosophy at his alma mater. During his last years he was chiefly occupied by the study of religion and metaphysics. He is perhaps best known for his championship of the doctrine of pragmatism inaugurated by C. S. Peirce of Cambridge, Miassachussets, according to which the value of any assertion is tested by its practical bearing upon human interests and purposes. He died on August 27, 1910. His principal publications were "Principles of Psychology" (1890), "Talks to Teachers on Psychology (1899), "Varieties of Religious Experience" (1902), and "Pragmatism" (1907). Numerous honours were conferred upon him at home and abroad, including membership of the National Academies of America, France, Italy, Prussia and Denmark, doctorate of letters at Padua and Durham, doctorate of laws at Harvard., Princeton and Edinburgh, and doctorate of science at Oxford and Geneva.

\section{Association of Special Libraries and Information Bureaux}

THE sixteenth annual general meeting of the Association of Special Libraries and Information Bureaux was held on December 13, 1941. The chair was taken by the president, Sir Harry Lindsay, director of the Imperial Institute, whose introductory remarks touched on the widening scope of the Association's activities, a subject that was further developed by Mr. E. J. Carter, the honorary" secretary, in his review of the year's work. The Association was fortunate enough to come through the winter's air-raids with only minor damage to the office; membership has remained steady and publications continued as usual. New opportunities for service arising from war conditions have been seized, among which was the investigation into the location and supply of scientific and technical periodicals now reaching the country from enemy and enemyoccupied territories, a survey carried out under the auspices of the Royal Society and the Rockefeller Foundation. Further details of the information thus compiled can be obtained on application to the ASLIB Oifice at 31, Museum Street, London, W.C.1. Other projects for bibliographical co-ordination are being considered.

\section{Medical History of the War}

An editorial board, under the chairmanship of the President of the Board of Education and composed of representatives of the Fighting Services, the Ministry of Health, the Department of Health for Scotland, the Committee of Imperial Defence and the Medical Research Council, has been set up by the War Cabinet to direct the preparation of a "Medical History of the War". The Board met recently and discussed the scope and planning of this undertaking, the value of which as a record of medical work during the War and of the War's contribution to medical science, will be appreciated. Sir Arthur MacNalty, until recently chief medical officer of the Ministry of Health, has been appointed editor-in-chief. The collection and classification of material for the "History" has now begun. The Editorial Board would be glad to receive copies of published articles, reports and other information from medical officers of health and medical practitioners which may be of use in assembling material for the medical historians; such data should be communicated to the Editor-in-Chief, Medical History of the War, Room 208, Caxton House West, Tothill Street, London, S.W.1.

\section{Announcements}

IT is announced by the New York correspondent of The Times that the Mount Palomar Observatory, in California, which is to house the 200 -in. telescope, will be closed on January 15 and will remain closed for the duration of the War.

Prof. Louis F. Fieser, professor of organic chemistry in Harvard University, has been awarded the Kathleen Berkan Judd one thousand dollar prize of the Memorial Hospital for the Treatment of Cancer and Allied Diseases, New York City, in recognition of his contributions to cancer research. Prof. Fieser's work in this connexion has dealt chiefly with chemistry and synthesis of carcinogenic compounds. 